Sharif University of Technology
Scientia Iranica
SCIENTIA
IRAN I CA
http://scientiairanica.sharif.edu

\title{
Proximity effects between two plus-plan shaped high-rise buildings on mean and RMS pressure coefficients
}

\author{
S.K. Nagar, R. Raj*, and N. Dev \\ Department of Civil Engineering, Delhi Technological University, Delhi, Zip Code: 110042, India.
}

Received 12 May 2020; received in revised form 28 March 2021; accepted 5 July 2021

\section{KEYWORDS \\ Tall buildings; \\ Interference effect; \\ Wind load; \\ Wind tunnel; \\ Mean pressure \\ coefficient; \\ Interference factor.}

\begin{abstract}
Wind-induced interference effects may result in a substantial increase or reduction in wind forces on the buildings constructed in groups due to the modification of wind flow according to the shape and relative position of the buildings. The present study aims to conduct an experimental study of wind-generated proximity effects on both mean and Root Mean Square (RMS) pressure coefficients between two tall buildings in detail under different interference conditions. The Interference effects on the mean and RMS pressure coefficients are regarded as interference factors, i.e., Mean Interference Factor (MIF) and RMS Interference Factor (RIF). The results demonstrate that the interference effects on the local wind pressure are significantly higher on the windward side faces near the recessed corner. Full blockage condition generates suction on walls facing the gap. Half blockage and no blockage conditions create a more severe interference effect than the full blockage. The maximum values of MIF are 4, 9, and 13 in full, half, and no blockage conditions, respectively. Interference effects result in reduced wind load on side faces and leeward side faces. Suction at side faces is reduced by $65 \%$ approximately in the full blockage condition. RIF values less than unity are observed for all interference cases.

(C) 2022 Sharif University of Technology. All rights reserved.
\end{abstract}

\section{Introduction}

With rapid urbanization and shortage of land in urban areas, modern high-rise buildings are often constructed in groups. When several high-rise structures are situated in the vicinity of each other, compared to isolated buildings, the wind flow patterns around the buildings are quite intricate due to interaction effects. This may cause a contrary wind effect in such areas depending on the shape of the buildings due to the significant role of the shape of tall buildings in generating wind load on high-rise buildings. This problem is likely to be signifi-

*. Corresponding author. Tel.: +91-96500 59954

E-mail address: rituraj@dtu.ac.in (R.Raj) cantly threatening in the future due to the increasingly dense arrangement of buildings in cities because of land shortage. Guidelines for estimating the wind loads on tall buildings in the current design codes and standards are only available for regular and symmetric shapes. Furthermore, codes and standards offer minor guidance regarding the proximity effect for unconventional planshaped buildings. Since the wind effects depend on the shape and size of buildings, their relative positions, wind direction, etc. are also involved $[1,2]$; hence, it is challenging to provide a compendious and generalized set of recommendations for modification in wind load in the presence of adjacent buildings. Therefore, the proximity effect caused by nearby structures should be appropriately investigated for a realistic design of buildings considering wind [3].

Many researchers have studied the proximity ef- 
fects between tall buildings [4-19]. Behera et al. [20] studied the proximity effect between high-rise buildings with different plan ratios and interfering building positions. They observed that interference effects were beneficial with respect to the maximum positive pressure, yet the minimum negative pressure significantly increased. Dongmei et al. [21] assessed the interference factors of global aerodynamics and local wind pressure as well as the lift spectra of a square building in the presence of a lower-height building with the same cross-section at different positions. It was observed that in the oblique upstream position of the interfering building, fluctuating aerodynamic forces on the principal building increased significantly. Kim et al. [22,23] analyzed the effect of a structural link on the lateral wind response of two square-linked buildings. Results indicated that at a small gap between buildings, channeling was strong and the linked building system acted as a single bluff body. Kim et al. [24] studied the effect of the gap distance on the wind flow around linked buildings. The results also showed that for a parallel arrangement of buildings, single vortex street and biased flow were observed for a small gap between buildings at 0 -degree wind incidence. Lam et al. [25] studied the proximity effects on the closely spaced square buildings under different wind angles and gap distances among those buildings. They concluded that there was strong channeling through the building gaps caused by close proximity. Xie and $\mathrm{Gu}$ [13] studied the mean proximity effects between a group of two and three tall buildings. They concluded that shielding caused by upstream building reduced the mean wind forces on the principal building. Yan and Li [26] studied the interference effects between a pair of aerodynamically modified super-tall buildings. The obtained results showed that the dynamic response was substantially enlarged in a critical arrangement. $\mathrm{Yu}$ et al. [27] developed a relationship between the interference factor and spacing through high-precision regression equations for interference effects between two buildings with different arrangements. According to their findings, the interference effect was beneficial for the mean pressure, but the peak pressure at the lateral façade near the interfering building was amplified. Zhao and Lam [28] evaluated the interference effects between five square tall buildings in the wind tunnel, arranging them in L- and T-shaped patterns. As observed, there was a strong interference effect on all member buildings which, compared to the isolated buildings, significantly modified wind loads . Zu and Lam [29] studied the shielding effect on building a square plan in the presence of a row of low- or mediumrise buildings and concluded that at a normal incidence angle, the mean along wind loads on the principal tall building was always reduced.

Hui et al. [30,31] investigated the mutual interfer- ence effects on the local peak pressure coefficients between two high-rise building models of different shapes. They observed that the proximity effects were considerably dependent on building shapes, configuration, and wind angles. The smallest minimum peak pressure at the face increased up to $40 \%$. Kim et al. [32] studied the Interference effects on the local peak pressures for different wind incidence angles and height ratios of interfering buildings. Their results showed that the peak suction enlarged at a higher height ratio. Oblique arrangement generates more severe peak suction than tandem configuration. Micháček et al. [33] studied the aerodynamic interference between three cylindrical buildings in a row surrounded by small buildings. The experimental results confirmed a substantial increase in the local pressure. Mara et al. [10] performed wind tunnel tests to assess the proximity effects between two buildings of similar heights and geometries associated with the square plan building of interest. Aerodynamic interference factors greater than unity were observed for Root Mean Square (RMS) cross-wind forces for the direct upstream location of the interfering building.

Flaga et al. [34] evaluated the effect of interference between closely spaced irregular-shaped tall buildings exposed to wind on the mean pressure distribution, global forces, and pedestrian comfort. They found that a close proximity between buildings could generate highly negative peak pressure on the surfaces facing the gap. Kar and Dalui [35] investigated the wind interference effects in the mean pressure coefficients on an irregularly shaped building due to a group of three square plan buildings of equal heights at different locations in along-wind and across-wind directions. $\mathrm{Li}$ and $\mathrm{Li}$ [36] evaluated the interference effect on the irregularly shaped twin-tall tapered buildings with recessed corners. As observed, the proximity effects between tapered buildings were considerably different from those of the square buildings. Nagar et al. [37] examined the proximity effects between closely spaced square and $\mathrm{H}$ plan shape twin tall buildings. They highlighted that the interfering building could generate suction at windward of the principal building when the interfering building was at upstream. Zhang et al. [38] analyzed the interference effects between two linked " $H$ " type twin-tower structures. They concluded that the channeling effect of the surrounding buildings was the main source of maximum cross-bridge displacement.

Chen et al. [39] and Quan et al. [40] studied the proximity effects on an existing target tall building surrounded by the proposed super tall building and a pair of adjacent buildings of similar height. The results indicated that the aerodynamic response of the target building considerably increased when the proposed super-tall building was at upstream. Farhadi and Rehnama [41] studied the flow along a surface- 
attached cube using numerical simulations. Jing et al. [42] analyzed the proximity effects between two oil storage tanks on wind fields and dynamic response due to the wind effects. According to their findings, the pressure acting on the tank under interference was notably higher than that of single one. Liang et al. [43] examined the interference effects of the wind pressure on the windward facade of the principal building by using wind tunnel tests. As observed, variations of the relative position of the secondary building could change the bimodal distribution into a unimodal form. Sun et al. [44] conducted pressure measurement tests to study the proximity effects between two chimneys with different distances and wind angles. They concluded that interference effects were significantly more intense on the across-wind load than those on the alongwind load. The maximum interference factor for the extreme across-wind response was 1.9. Tavakol and Yaghoubi [45] investigated the flow around a surface-mounted hemisphere. The study was done experimentally and numerically, and flow patterns were studied for different flow velocities in different sections. Xing and Qian [16] numerically studied the flow around a group of three circular cylinders arranged in equilateral-triangle arrangements. They observed that the wake at the back of two parallel cylinders downstream of the three was asymmetrical at small spacing, which disappeared upon an increase in the spacing ratios.

Despite the extensive literature on the interference effects between buildings with square, rectangular, or circular sections $[1,8,9,12,16,18,31,32,43,46-53]$, the interference effects between unconventional plan tall buildings has been rarely studied [26,35-39,54]. In addition, very few studies have been conducted on the proximity effects between closely spaced tall buildings $[23-25,28,34,38]$. Therefore, these findings need further investigations for a pair of high-rise buildings with unconventional plans. Large-sized recessed corners are generally considered in twin residential tall buildings to provide amenities, allow ventilation into washrooms and kitchens, and offer maximum views to all apartments [55]. The study of interference effects between the closely spaced plus-plan-shaped tall buildings with large-sized recessed corners has not yet been conducted. To this end, this study centers on the wind-induced proximity effects between two identical plus-plan-shaped high-rise buildings on the mean and RMS pressure coefficients.

The present study examines three different arrangements of the interfering building that provide full blockage, half blockage, and no blockage conditions for the principal building. The interference effects on the mean and RMS wind pressure coefficients are regarded as Mean Interference Factor (MIF) and RMS Interference Factor (RIF) for the three interference conditions. The contours of the interference factors greater than one at critical faces are also presented.

\section{Experimental setup}

\subsection{Approach wind characteristics}

The tests were carried out in an open circuit Boundary Layer Wind Tunnel (BLWT) at the Civil Department of the Indian Institute of Technology Roorkee, Roorkee, India. The tunnel was equipped with a single fan to generate uninterrupted flow which was operated by 125 HP motor. The working section of the tunnel was $15 \mathrm{~m}$ long with a cross-section of $2 \mathrm{~m}$, and its total length was $38 \mathrm{~m}$ (Figure 1). Wind flow characteristics were simulated similar to the conditions of IS 875: Part 3 (IS 875 Part 3, 2015) by placing vortex generators, cubical blocks, and barrier wall in the inlet region.

The mean Velocity $(V)$ and Turbulence Intensity (TI) profile inside the tunnel are simulated with a power law index of $(\alpha)=0.22$ for the current study. Models were placed at the center of the turntable, located $12.21 \mathrm{~m}$ from the elliptical effuse, which could rotate to set the angle of wind incidence. A dyno drive attached to the diffuser or fan at the outlet of the tunnel was used to vary the wind speed in the tunnel with a maximum speed of $20 \mathrm{~m} / \mathrm{s}$. Figure 2 presents the velocity profile measured at the downstream end of the tunnel and variation of the TI of the flow. The TI near the floor of the wind tunnel was found to be about $12 \%$, and wind velocity at building height was $9.87 \mathrm{~m} / \mathrm{sec}$. The wind speed in the wind tunnel was evaluated using "TESTO-480". A probe was connected to this instrument to measure the wind velocity at a different height, which had a length of $1 \mathrm{~m}$. This instrument was connected to and operated through a computer. The wind pressure on the models was measured using a "Baratron Pressure Transducer", which was capable of measuring extremely low differential heads.

\subsection{Details of model}

The experimental building models considered in this study comprise two buildings: one is the rigid pressure model for the principal building under consideration, and the second is the wooden model of an interfering building. The principal building model was made of a transparent Perspex sheet with thickness of $4 \mathrm{~mm}$ and stiff faces to ensure sufficient rigidity and strength of the model. The interfering building model was a wooden model of similar shape and size without pressure taping (Figure 3). The length scale was set as 1:300 to study the model with the Plan area of $40,000 \mathrm{~mm}^{2}$ and height of $600 \mathrm{~mm}$ in the wind tunnel. Pressure tapings were made of steel tubes with an internal diameter of $1 \mathrm{~mm}$ and length of 15 $20 \mathrm{~mm}$. The total number of 196 pressure taping was installed on the wall of the pressure model, located at 

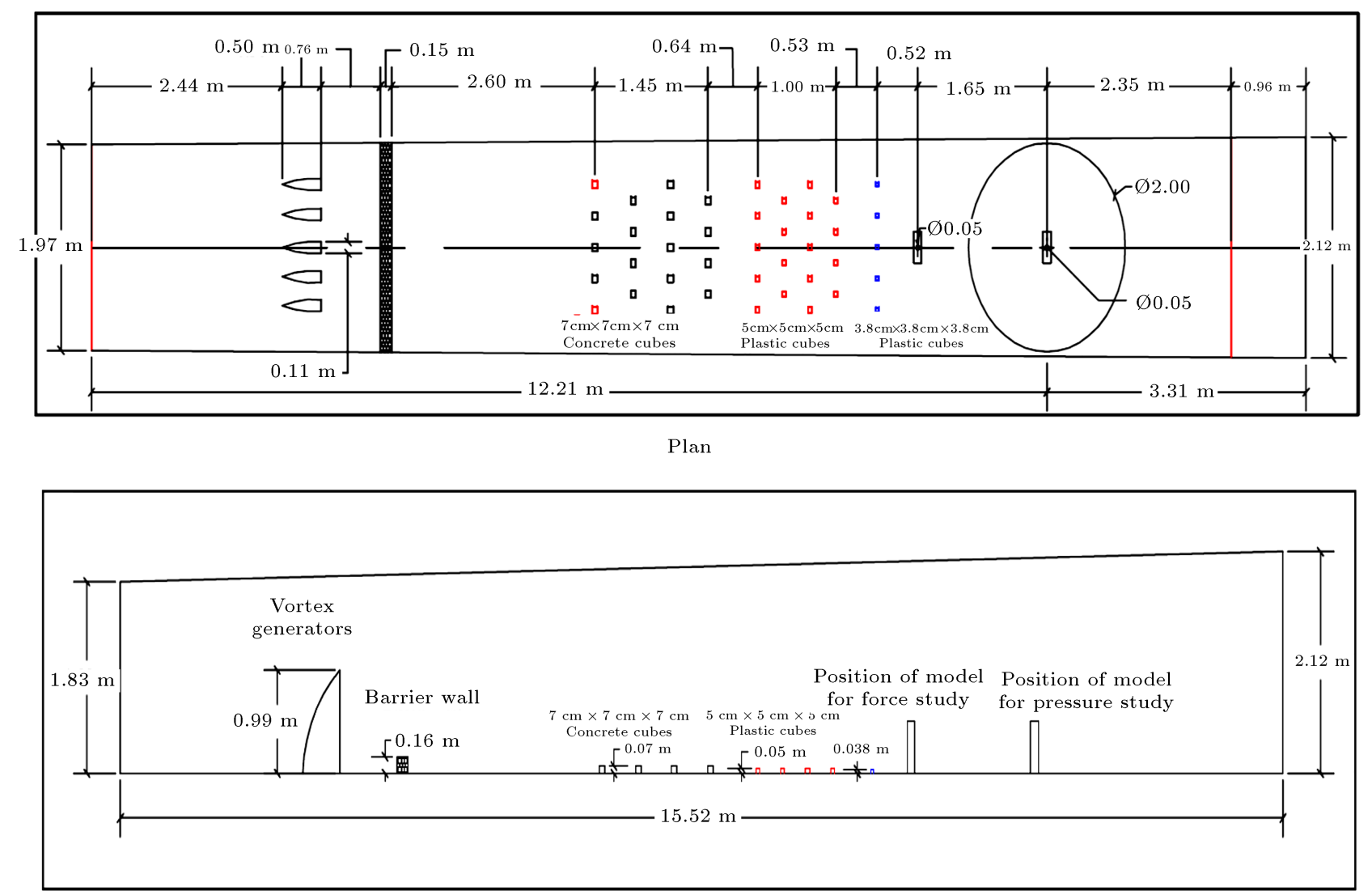

Elevation

Figure 1. Wind tunnel layout.

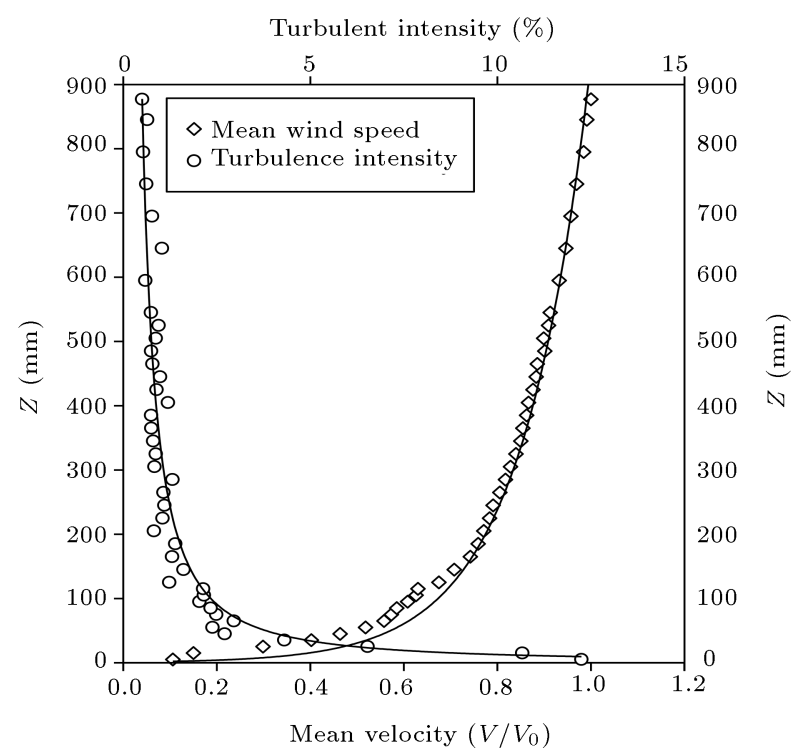

Figure 2. Mean velocity and Turbulence Intensity (TI) profile.

seven different height levels of 10, 60, 180, 300, 420, 540 , and $590 \mathrm{~mm}$ (Level G-A) from the bottom, as shown in Figure 4(a), to ensure proper distribution of wind pressure on all surfaces. There were a total of 28 measuring points at each level (Figure 4(b)).

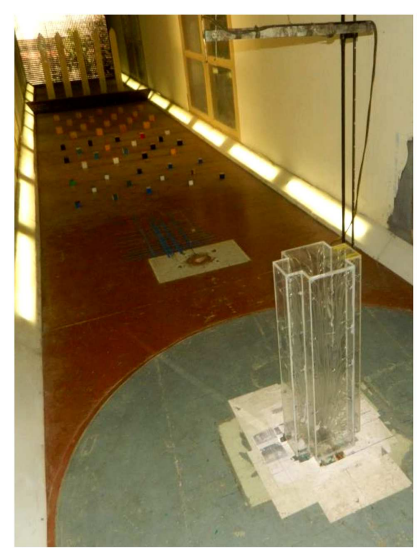

(a) Isolate

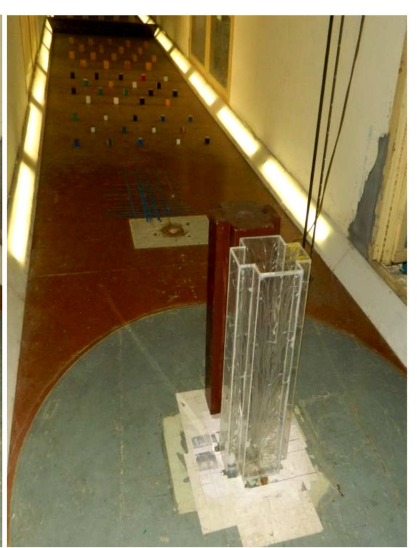

(b) Interference
Figure 3. Rigid pressure models in the wind tunnel.

Figure 4(c) illustrates the plan showing different faces and detailed dimensions.

\subsection{Pressure measurement}

Four sets of test arrangements were prepared for measuring the pressure and interference effect between building models. In Set 1, the principal building was tested in an isolated condition with face $\mathrm{A}$ as a windward face, as shown in Figure 4(c). Set 2 to Set 4 are depicted in Figure 5, which shows different 


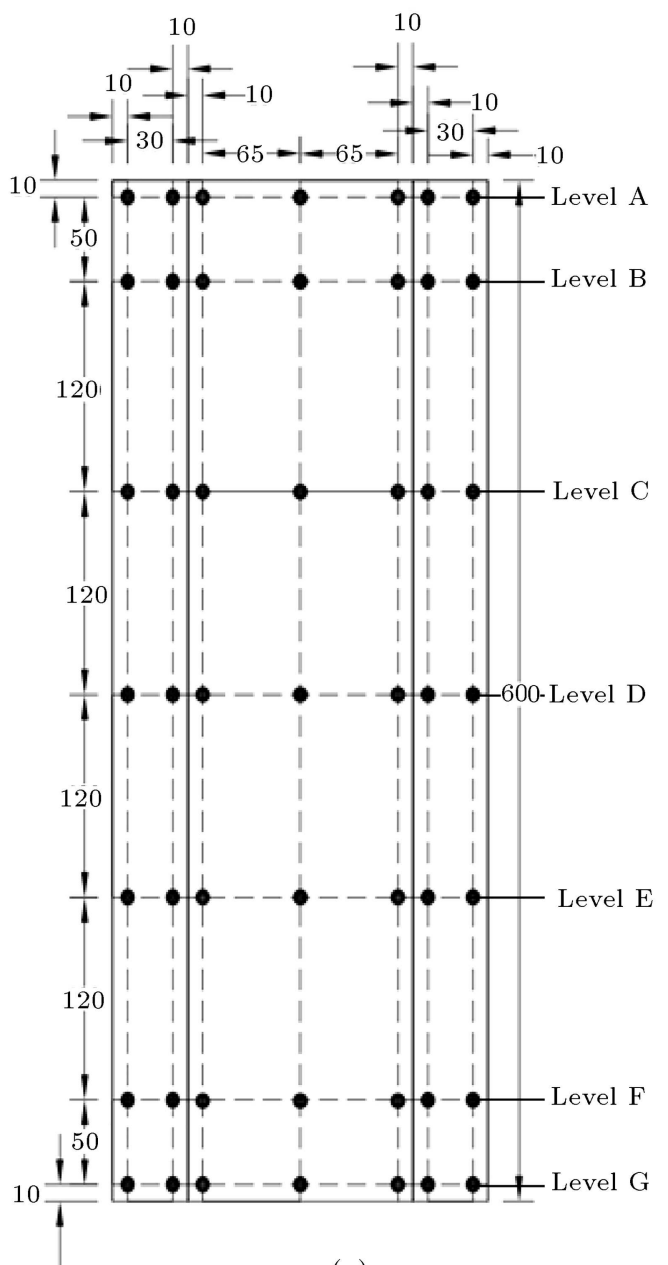

(a)

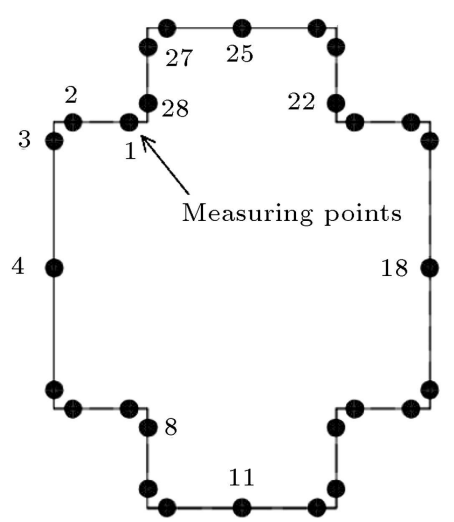

(b)

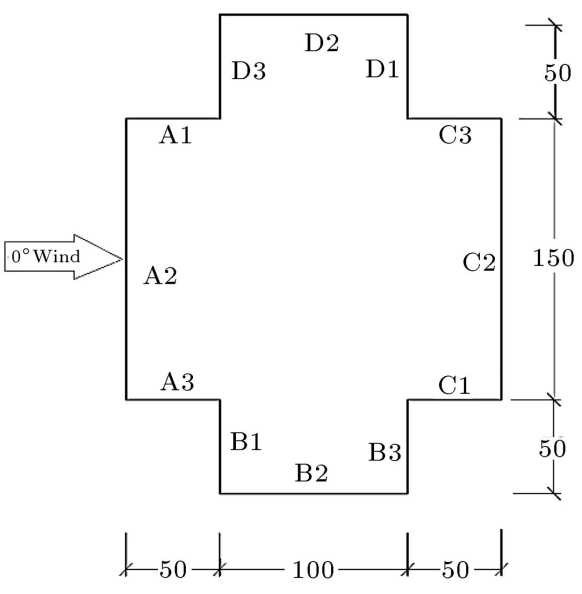

(c)

Figure 4. (a) Pressure tapping levels (unit: mm). (b) Pressure tap distribution at each layer. (c) Plan dimension and building faces (unit: $\mathrm{mm}$ ).

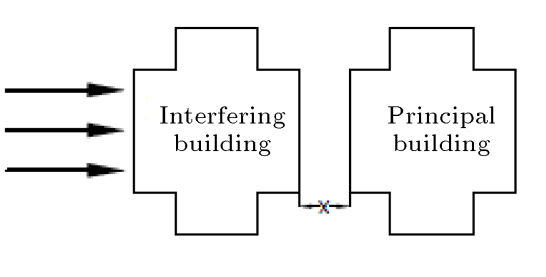

(a)

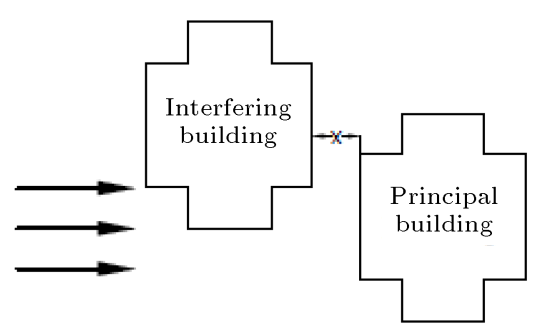

(b)

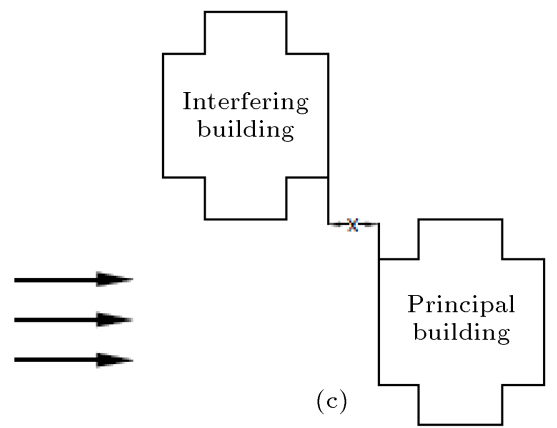

Figure 5. Interference conditions: (a) Full blockage, (b) half blockage, and (c) no blockage.

positions of the interfering buildings with respect to the principal building. In Set 2, the interfering building was positioned in line with the principal building. Distance $(x)$ between the principal and interfering buildings was kept equal to $60 \mathrm{~mm}(1 / 10$ th of the model height) for all cases. In Set 3 and Set 4 , the interfering building was positioned in oblique arrangement, thus creating half blockage and no blockage conditions for the principal building, respectively. The value of the mean pressure coefficient $\left(C_{p, \text { mean }}\right)$ at any pressure measuring point was calculated by normalizing the measuring pressure at the corresponding measuring point based on the following equation:

$$
\bar{c}_{P}=\frac{\bar{P}-P_{\text {static }}}{P_{\text {dyn }}},
$$

where $\bar{P}$ is the mean pressure; $P_{\text {static }}$ the static pressure at the reference height; $P_{\text {dyn }}$ the pressure at the refer- 
ence point given by $\frac{1}{2} \rho_{a} U^{2}, U$ the reference velocity at the reference height.

For the fluctuating pressure, the RMS pressure coefficient $\left(C_{p, r m s}\right)$ was calculated using the following expression [3]:

$$
C_{p, r m s}=\sqrt{\sum_{K=1}^{N}\left(C_{p k}-C_{p, \text { mean }}\right)^{2} /(N-1)},
$$

where $C_{p k}$ is the time history of the pressure measuring point, $N$ the total number of samples, and $C_{p \text {,mean }}$ the mean pressure coefficient.

\section{Results and analysis}

\subsection{Data validation}

Before proceeding to study the distribution of pressure on the plus-plan-shaped building, it is necessary to verify the calculation method used for wind loading measurements. The experimental parameters of a base square building model with the aspect ratio of 1:5 at 0 -degree wind incidence were compared with the experimental parameter [56-58] of the classical model of Commonwealth Advisory Aeronautical Research Council (CAARC) standard tall building model tested at several research institutions, including the University of Bristol (BU), Monash University (MU), National Aeronautical Establishment (NAE), and National Physical Laboratory. Figure 6 presents a comparison of $C_{p \text {,mean }}$ at $0.7 \mathrm{H}$ height of the square building model with the $C_{p \text {,mean }}$ of the CAARC standard tall building model at $2 / 3 \mathrm{H}$. The mean wind pressure coefficients obtained from this study for the reference square building model are consistent with those of the CAARC model.

3.2. Mean and RMS wind pressure coefficients Prediction of wind load is a difficult task with interfering buildings in the vicinity of each other. The relative

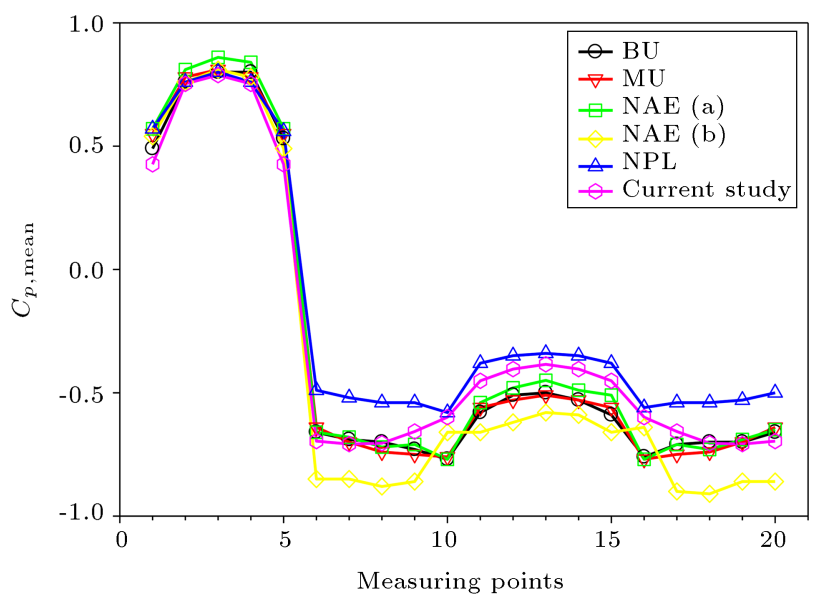

Figure 6. Comparison of $C_{p, \text { mean }}$ of reference square model with Common Wealth Advisory Aeronautical Research Council (CAARC) standard models. location of these interfering buildings is an essential parameter that affects the characteristics of the wind load on the principal building. A detailed study of both isolated and interference conditions is done to investigate the distribution of $C_{p \text {,mean }}$ and $C_{p, r m s}$ on the surfaces of the principal building. Results are presented as contours of $C_{p \text {,mean }}$ and $C_{p, r m s}$ on all faces.

\subsubsection{Isolated building condition}

The contours of $C_{p \text {,mean }}$ and $C_{p, r m s}$ on different faces corresponding to the isolated condition are shown in Figures 7 and 8, respectively. Here, only half of the surfaces are presented because similar pressure distribution occurs on symmetric surfaces due to the symmetry in plan and wind flow about the axis in the direction of the wind flow. The distribution of $C_{p \text {,mean }}$ is symmetric about the vertical centerline at the central windward and leeward faces, i.e., at faces $\mathrm{A} 2$ and $\mathrm{C} 2$, respectively. Pressure on the whole face A2 is positive. The maximum $C_{p \text {,mean }}$ is 0.58 with the face average value of 0.34 . While the high-pressure region is located on the central upper surface, the lower pressure region is located on the bottom of the side edges. Face C2 experiences suction with a small variation in pressure on face ranging from -0.44 to -0.54 . While the high value zone is located at the top, the low value zone is located at the central surface at $\mathrm{H} / 3$ from bottom. All the surfaces at side and leeward are under suction, as expected, due to the side wash and vortices generated in the wake. Front side faces A1 and A3 have maximum negative and average values of $C_{p \text {, mean }}-0.39$, and -0.20 , respectively. However, the leeward side faces $\mathrm{C} 1$ and $\mathrm{C} 3$ have an almost similar distribution of pressure throughout the face ranging between -0.47 and -0.58 with the average $C_{p \text {,mean }}$ -0.54 . Side front faces B1 and D3 have suction on inside edges, perhaps due to the formation of eddies at reentrant corners. Suction tends to reduce on the side faces B2 and D2 from windward edge to leeward edge, with the maximum and face average values of $C_{p \text {,mean }}-0.86$, and -0.69 , respectively. Distribution of $C_{p \text {,mean }}$ varies between -0.48 and -0.62 with the face average of -0.56 on leeward front face B3 and D1. The RMS pressure coefficients vary from .04 to 0.19 in the isolated building condition. The largest value of $C_{p, r m s}$ is observed on the side surface B2. Large values of fluctuating component are observed on the side faces and those adjacent to re-entrant corners due to the increased turbulence at the corners and edges of building on the windward side.

\subsubsection{Full blockage condition}

The distribution of $C_{p \text {,mean }}$, corresponding to the full blockage interference condition, is shown in Figure 9. The distribution of $C_{p \text {,mean }}$ on all surfaces of the princi- 


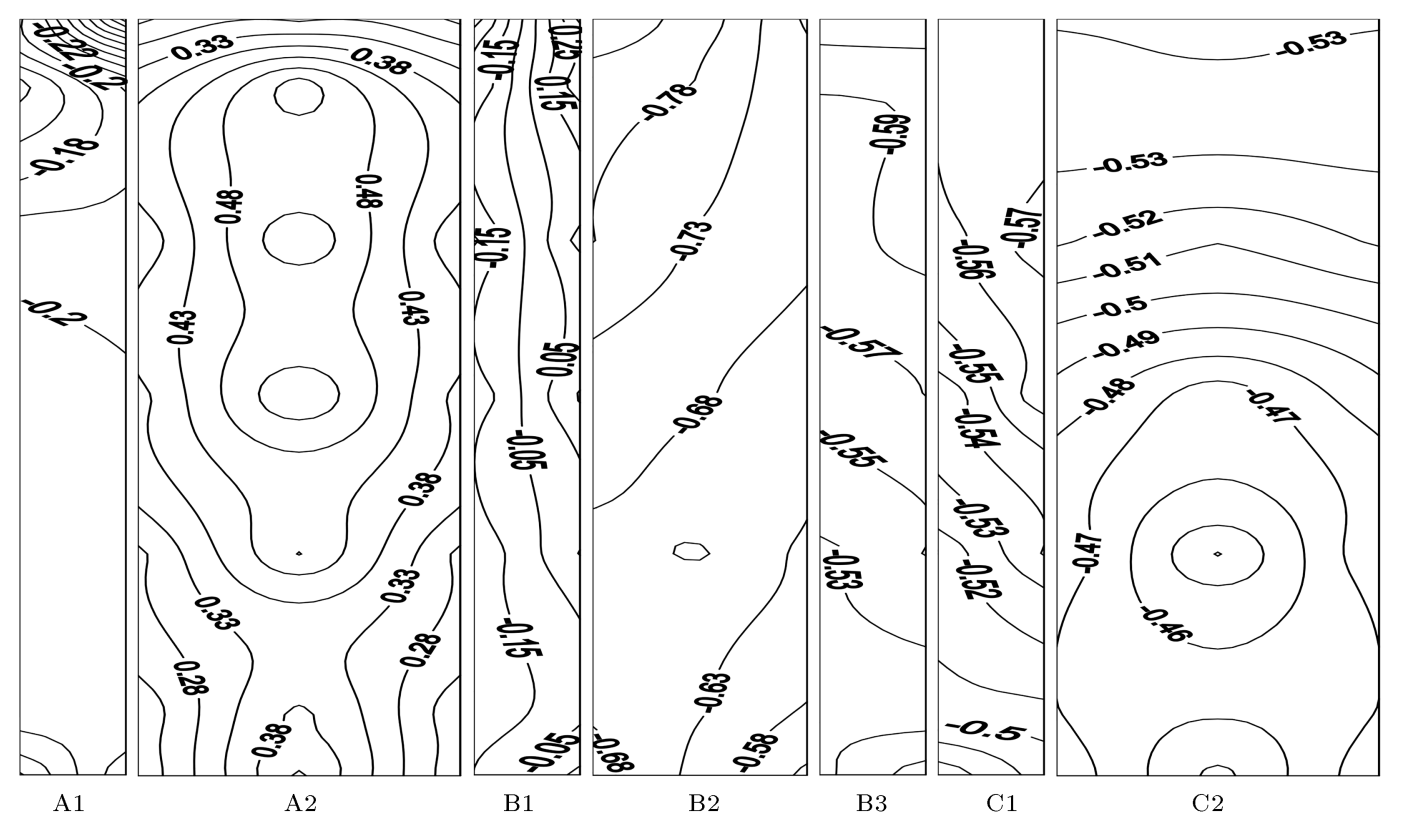

Figure 7. Distribution of mean pressure coefficients (isolated building).

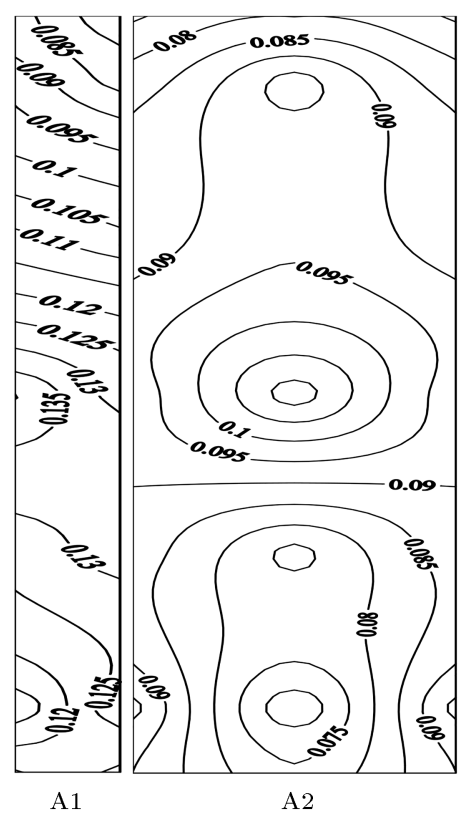

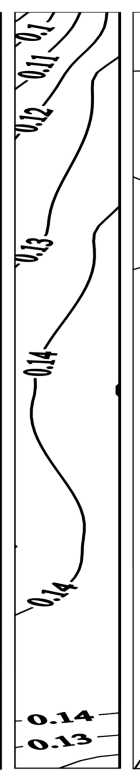

B1

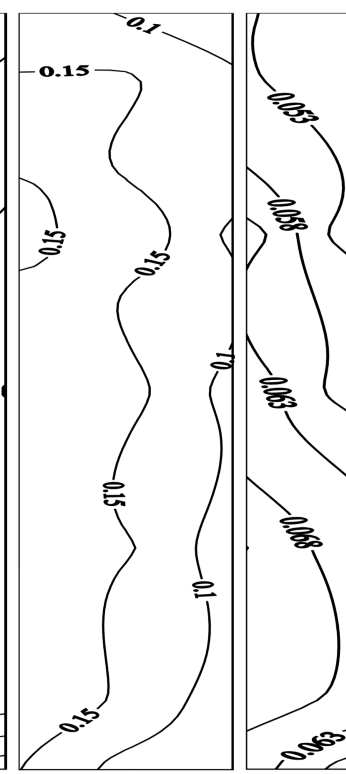

B3

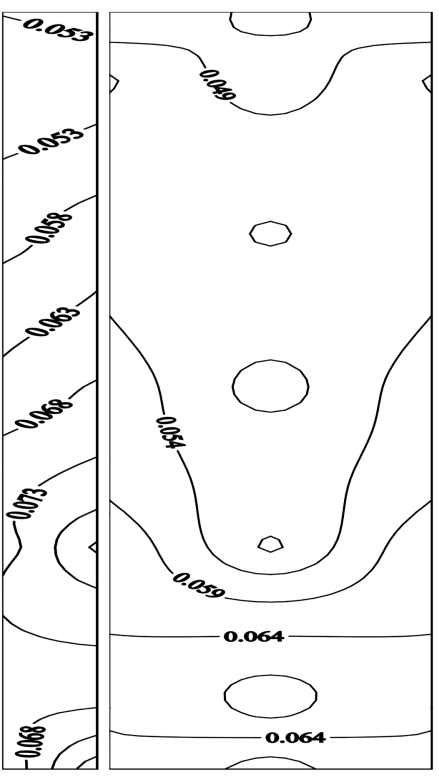

$\mathrm{C} 1$

$\mathrm{C} 2$

Figure 8. Distribution of RMS pressure coefficients (isolated building).

pal building in the presence of the interfering building, creating a full blockage condition for the principal building, is quite different from that of the isolated building. Pressure tends to increase with respect to height, like isolated buildings on the front face and decrease near the top edge. Strong interference effect affects the front faces because it is immersed in the wake of the interfering building, which causes suction on the front face A2, unlike isolated buildings, and the distribution of suction coefficient varies between -0.32 and -0.63 . The high suction zone is located at a height between $0.75 \mathrm{H}$ and $0.85 \mathrm{H}$. The absolute value is approximately $29 \%$ higher than that for the isolated building. The mean suction coefficient for the wind-ward face (B1 and D3) on the side significantly increased, compared to an isolated building. The suction coefficient increased by $51 \%$ on the windward side faces (A1 and A3), compared to the isolated building, which corresponded to the average of the face. However, suction decreased on leeward side faces (C1 and C3) with a small variation in the suction coefficient between -0.21 and -0.24 on the surface. 


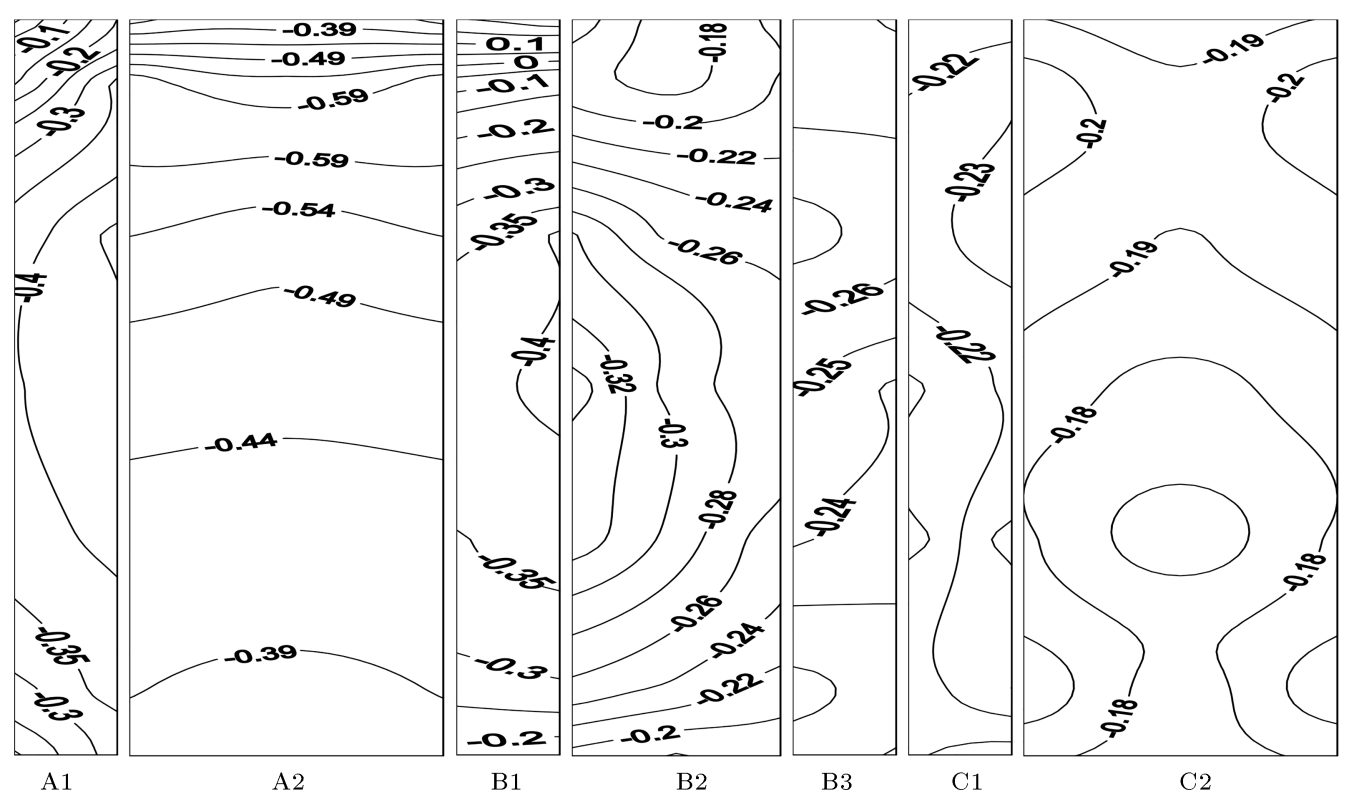

Figure 9. Distribution of mean pressure coefficients (full blockage).

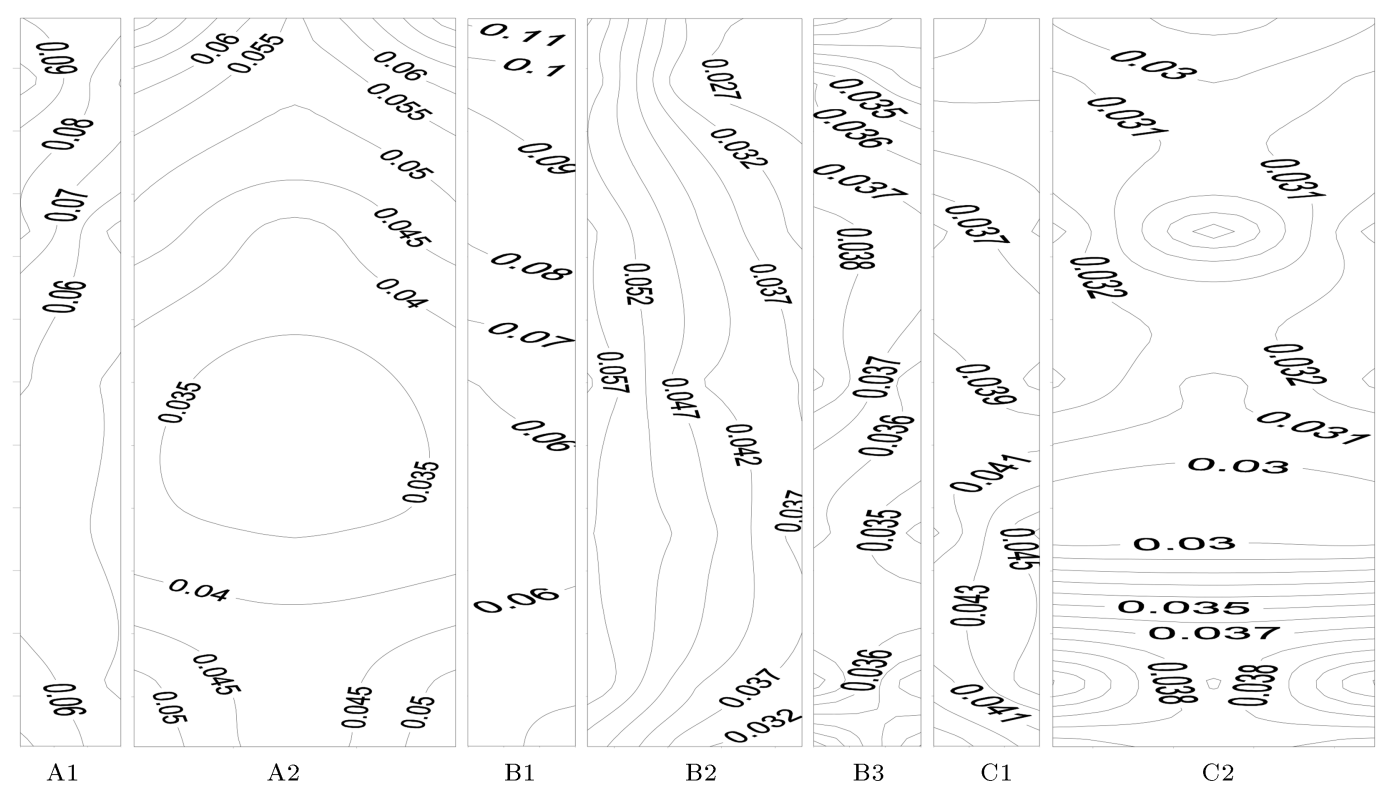

Figure 10. Distribution of RMS pressure coefficients (full blockage).

Such a considerable reduction (Approx. 65\%) was noticed in the suction on side faces (B2 and D2) and all leeward faces (B3, C1, C2, C3, and D1), and the reduction percentage ranged from $55 \%$ to $65 \%$. Suction coefficients on these side faces decreased from windward to leeward edge, and the maximum suction was reported at the middle height of the windward edge with $C_{p \text {,mean }}$. Distribution on the windward face A2 and leeward face $\mathrm{C} 2$ was symmetric about the vertical centerline.

As shown in Figure 10, the RMS pressure coefficient on all faces of the principal building under full blockage conditions significantly decreased, compared to the isolated building, and the maximum decrease was observed on the side faces from 0.13 to 0.04 . Compared to isolated building, the overall maximum face $C_{p, r m s}$ decreased on the faces attached to the reentrant corners on the windward side.

\subsubsection{Half blockage condition}

Figure 11 shows the distribution of $C_{p}$ and mean on all faces of the principal building under half-blockage interference conditions. Interfering buildings create asymmetrical wind flow around the principal building 


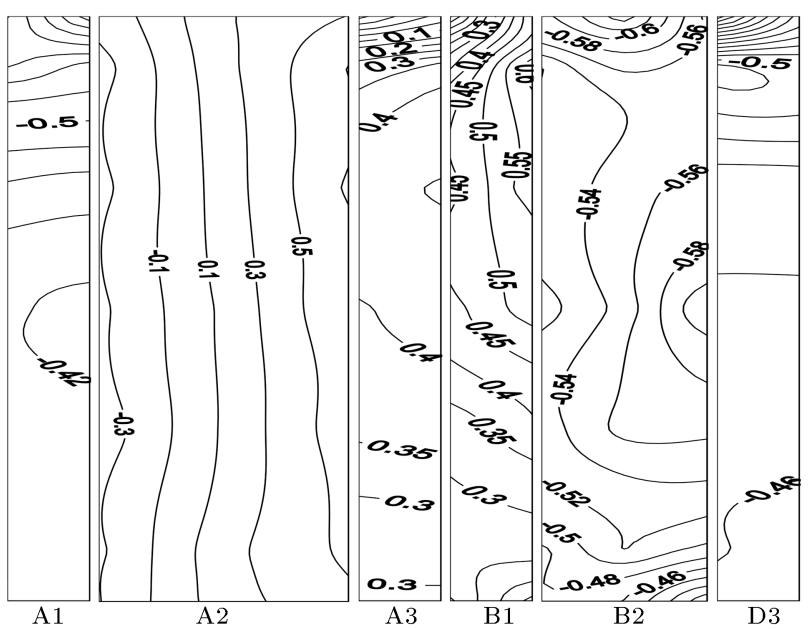

Figure 11. Distribution of $C_{p, \text { mean }}$ on windward faces (half blockage).

due to half-blockage conditions, thus making different pressure distributions on the symmetric faces. The interference effect on all faces depends on the face position in the wake area and orientation to the flow of wind. Active shielding is created by interfering buildings. Unlike isolated and full-blockage interference conditions, the distribution of pressure is not symmetrical about the vertical centerline on front face A2. Both sides are under the opposite nature of pressure. The surfaces towards the interfering building, which come under the wake region of the interfering building, are under suction. On the contrary, the opposite side has positive pressure. High-pressure zone is located near the right edge from bottom to top. Suction on the side face A1 at the center on the windward side increased, and the average $C_{p \text {,mean }}$ of the face was -0.47 , which was $57 \%$ higher than that of the isolated building. Front side face A3 has positive pressure, which has suction in isolated as well as full blockage conditions. While windward face B1 on the side endured positive pressure, face D3 was under increased suction, compared to the isolated building and full-blockage cases. The interference effect on all other faces is small, and the distribution of $C_{p \text {,mean }}$ is likely to be similar to that of the isolated building.

The fluctuating pressure component, as shown in Figure 12, decreased again significantly in the halfblockage interference position, compared to the isolated building for all faces. However, the maximum $C_{p, r m s}$ for face A1 increased by $58 \%$, compared to that in the isolated building, and doubled in the full-blockage building condition. For all other faces, the maximum $C_{p, r m s}$ decreased, compared to that in the isolated building.

\subsubsection{No blockage condition}

Contour plots of $C_{p \text {,mean }}$ and $C_{p, r m s}$ on all faces of the principal building in the case of no-blockage

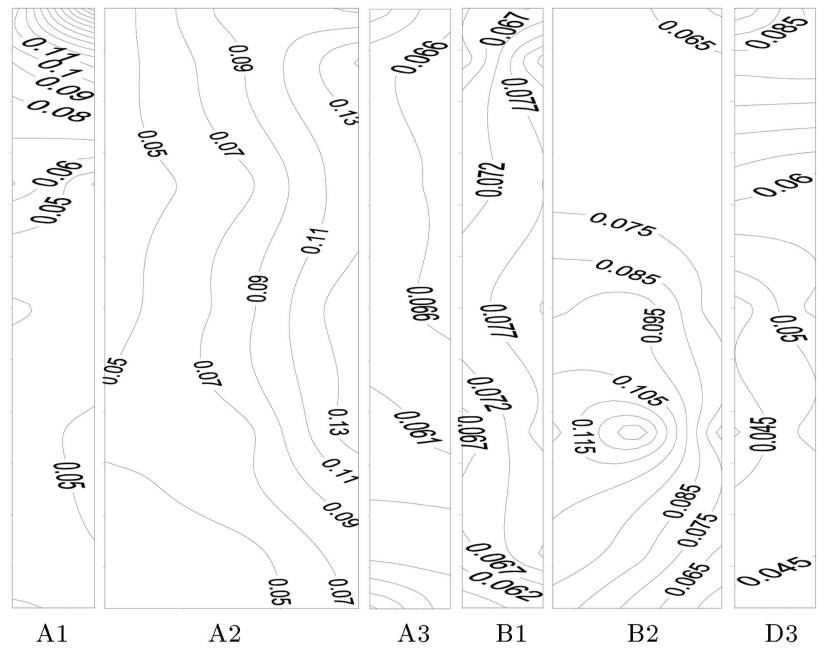

Figure 12. Distribution of $C_{p, \mathrm{rms}}$ on windward faces (half blockage).

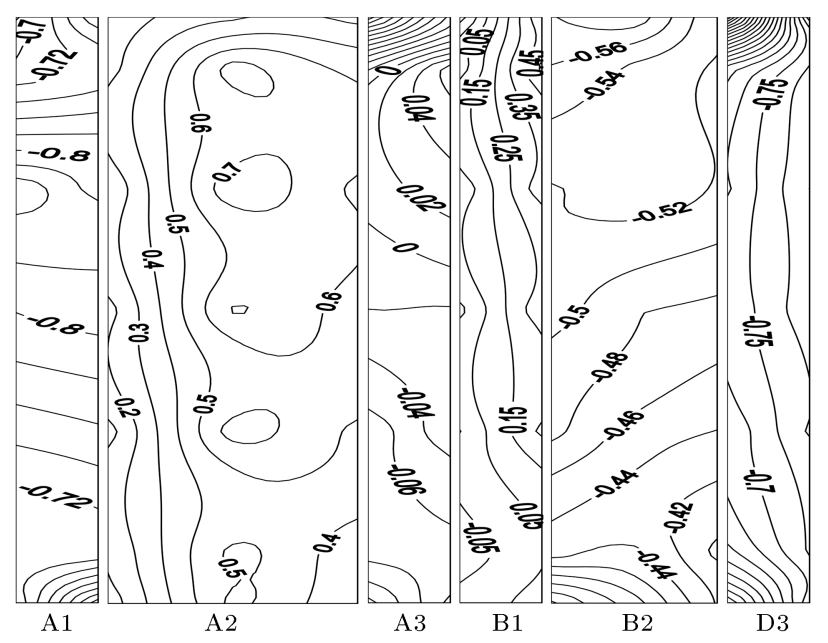

Figure 13. Distribution of $C_{p, \text { mean }}$ on windward faces (no blockage).

interference condition are shown in Figures 13 and 14, respectively. Interference effects for this location of the interfering building are critical for faces on the left side of the centerline along the windward direction mainly because faces on this side are also affected by the wake generated due to the existence of the nearby building. Suction on the front side face A1 increased significantly and reached its maximum value among isolated and all three interference conditions. The distribution of $C_{p \text {,mean }}$ varied from -0.68 to -0.86 with an average of -0.76 on the face, which was $60 \%$ higher than the half blockage condition. Pressure distribution on the front face A2 is similar to that in the half-blockage interference condition. The maximum and face average values of $C_{p \text {,mean }}$ for the front face D3 on the side towards the interfering building increased significantly by -0.89 and -0.65 , respectively, as compared to the isolated and all other interference conditions. The face 


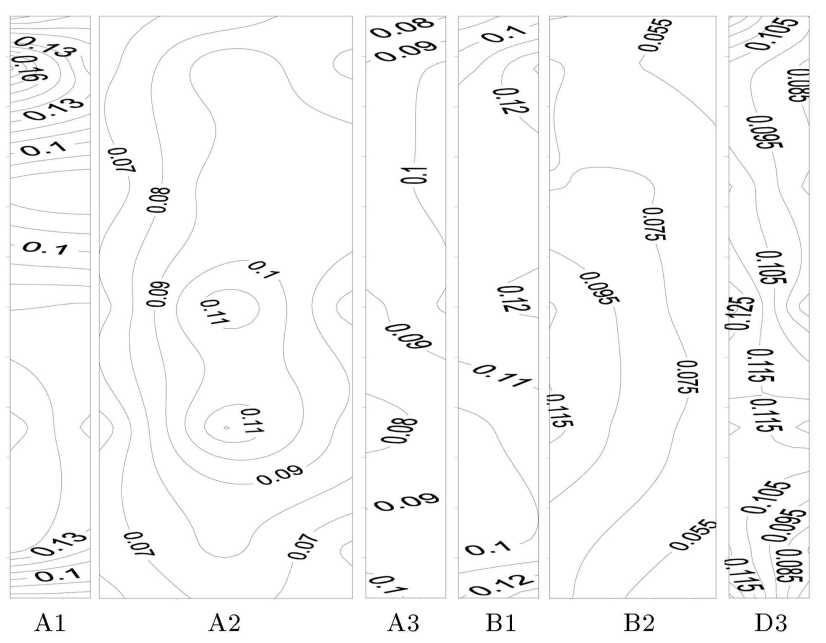

Figure 14. Distribution of $C_{p, r m s}$ on windward faces (no blockage).

average value for face D3 increased by $45 \%$ under halfblockage conditions. The interference effect on all other faces was favorable; in other words, it was reduced.

RMS pressure coefficient $C_{p, r m s}$ is either similar for most of the surfaces or reduced to that of isolated building case. The maximum value on face A1 has increased by $40 \%$ while it has decreased on other faces.

A detailed study of the mean and RMS pressure coefficients was conducted along the surface at each level of the principal building in isolated buildings as well as an interfering building in all three interference conditions. Figure 15 depicts the distribution of $C_{p \text {,mean }}$ along the measuring points at different levels for the isolated building and three different blockage conditions of interference. The fluctuation in $C_{p \text {,mean }}$ is significantly large for the measuring points which lie on faces at the front (i.e., at points 1 to 9,27 , and 28). The effect of re-entrant corners and edges can be seen in the figure clearly. Fluctuation in $C_{p \text {,mean }}$ at measuring points on faces at side and back is significantly small and absolute $C_{p \text {,mean }}$ is maximum for isolated buildings. It seems that the largest absolute value of $C_{p \text {,mean }}$ occurs for no blockage conditions at the bottom most level at $10 \mathrm{~mm}$ from the bottom.

The distribution of RMS pressure coefficients is shown in Figure 16 at different levels of the principal building. $C_{p, r m s}$ increases toward the central height of the building and is significant at middle levels, compared to the top and bottom levels except face A1. $C_{p, r m s}$ is reduced for leeward building sides, i.e., between measuring points 11 and 25 at each level for all conditions. For half blockage, the fluctuating component of pressure coefficient is significant at the windward edge of face A1 at level A; however, at level $\mathrm{B}$, it is significant for the no blockage condition near the corner on face A1. At the center height of the building, $C_{p, r m s}$ is greater and variation along the surface is also
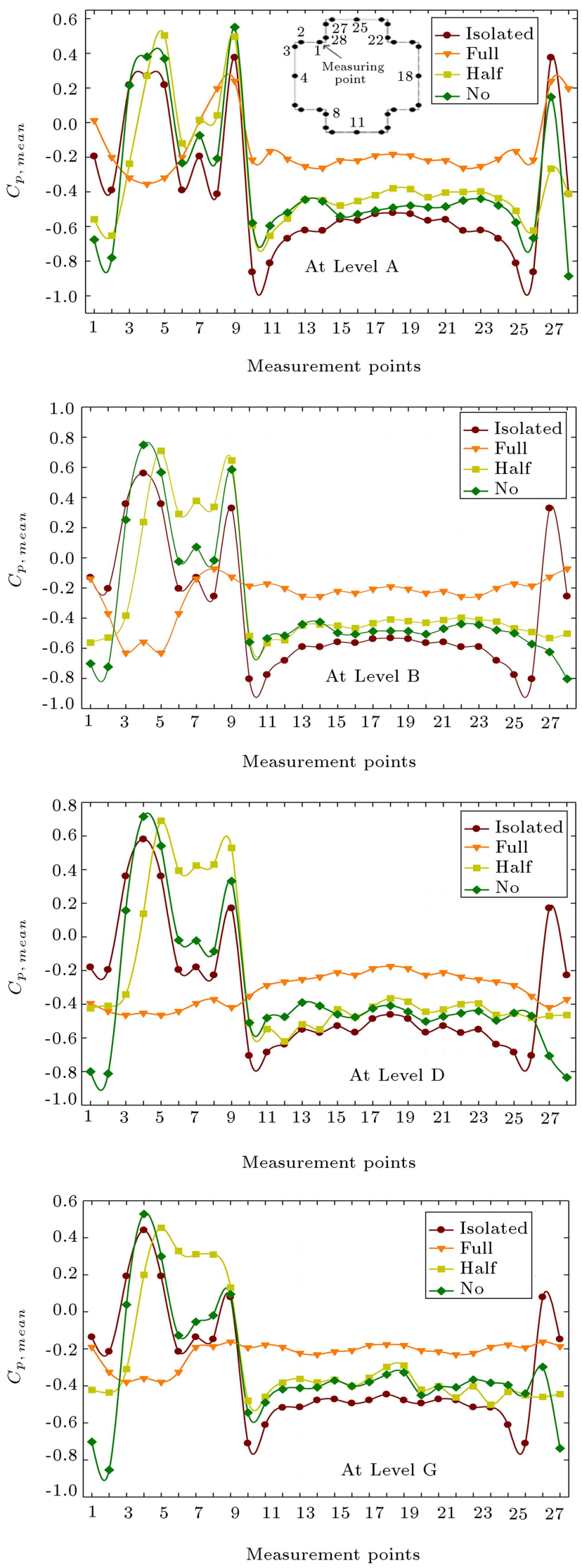

Figure 15. Mean pressure coefficients at different levels of principal buildings. 

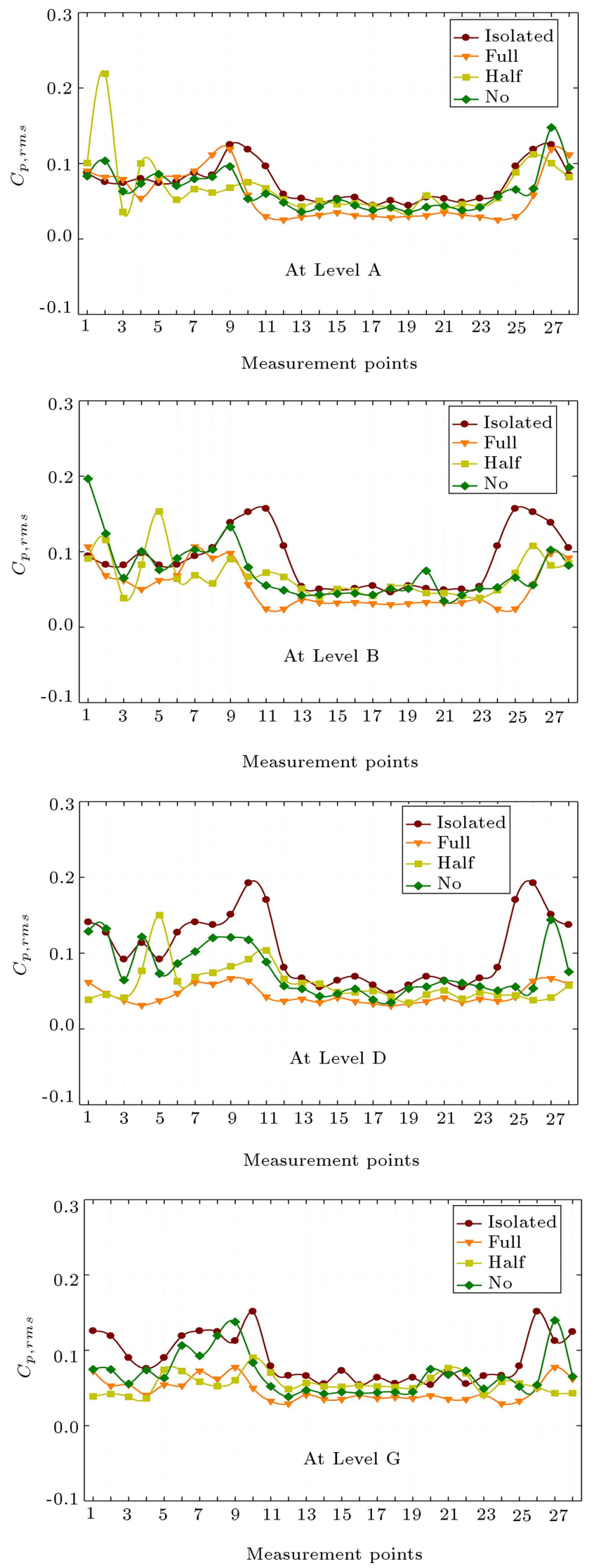

Figure 16. Root Mean Square (RMS) pressure coefficients at different levels of principal buildings. significant for isolated buildings. At the bottom level $\mathrm{G}$, distribution is similar to that of top-level A except for face A1 for half blockage.

\subsection{Interference factor}

The interference effects corresponding to different interference conditions on pressure coefficients $\left(C_{p}\right)$ related to all measurement points are of composite nature and challenging to present for all. To clarify the intricacy and to scrutinize the interference effects on $C_{p}$ in detail, Interference Factors (IF) for an average of $C_{p \text {,mean }}$ and $C_{p, r m s}$ on each face are proposed, as was given by Khanduri et al. [1], to point to the severity of interference effects on $C_{p \text {,mean }}$ and $C_{p, r m s}$ as follows:

$$
\begin{aligned}
& (M I F)=\frac{C_{p, \text { mean }} \text { with interfering building }}{C_{p, \text { mean }} \text { isolated building }}, \\
& (R I F)=\frac{C_{p, r m s} \text { with interfering building }}{C_{p, r m s} \text { isolated building }}
\end{aligned}
$$

where $M I F$ and $R I F$ are the interference factors in mean and RMS pressure coefficients, respectively. Figure 17

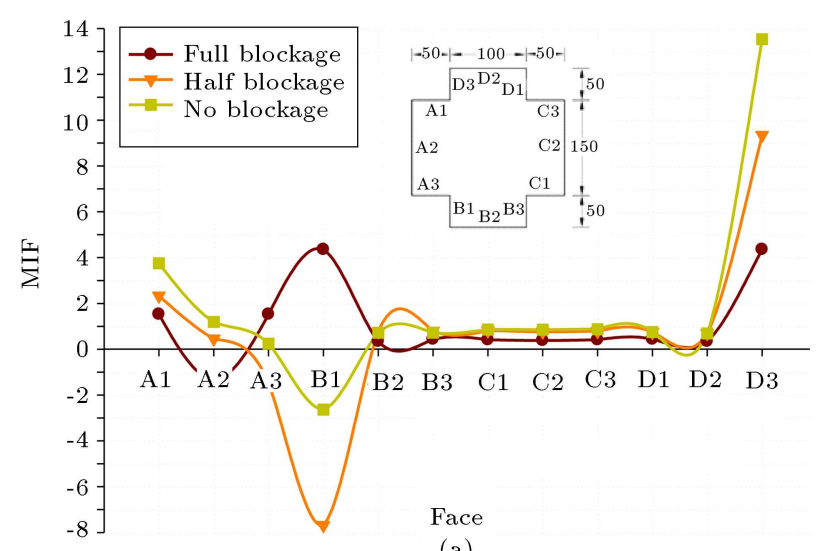

(a)

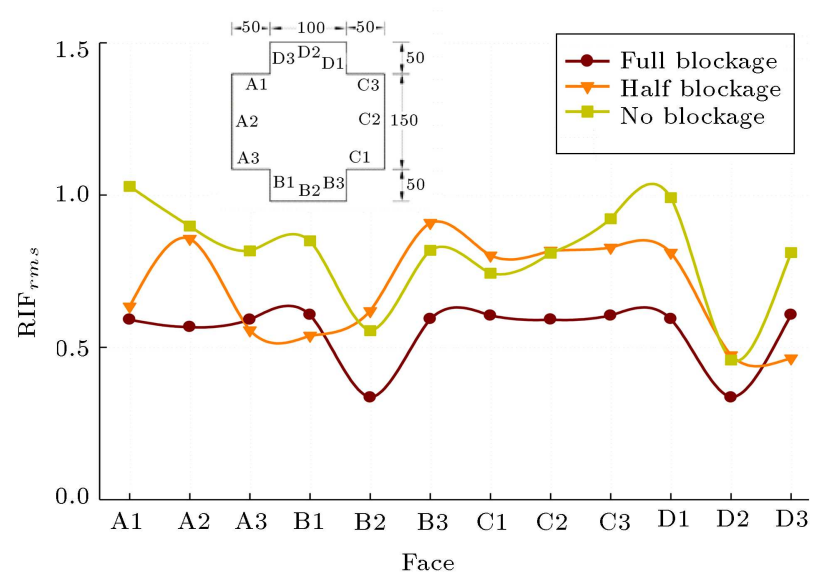

(b)

Figure 17. Interference factor on face: (a) Mean Interference Factor (MIF) and (b) RMS Interference Factor (RIF). 


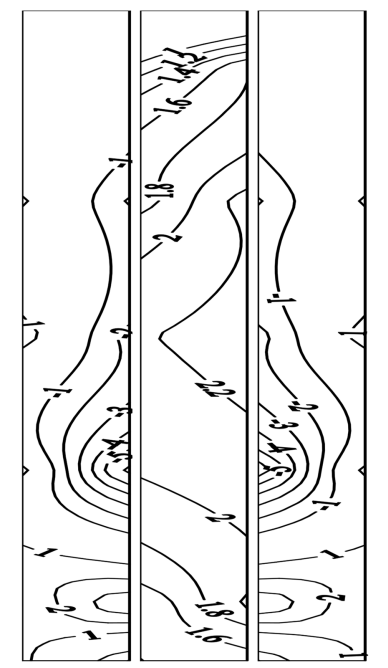

(a)

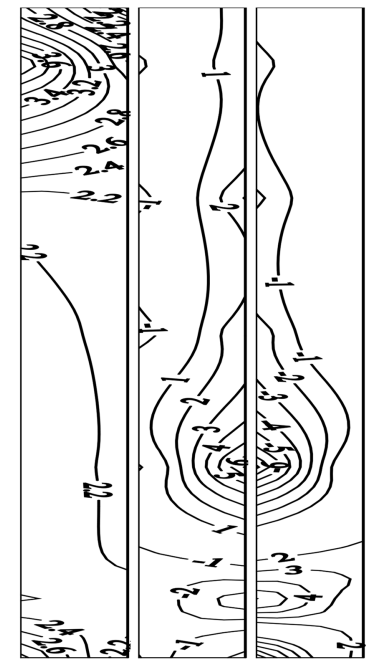

(b)

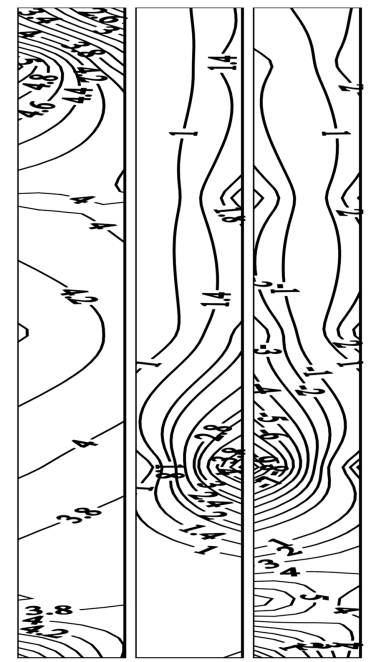

(c)

Figure 18. Mean Interference Factor (MIF) (I.F $\geq 1$ ) contour (left to right face A1, B1 and D3): (a) Full, (b) half, and (c) no blockage.

renders the variation of MIF and RIF along the different faces of the principal building starting from the front side face A1 to side front face D3 anticlock wise for all three interference conditions. From Figure 17(a), interference effects are significant for faces A1, B1, and D3 only. Interference effects for full blockage interference condition are critical at faces B1 and D3 only, for which MIF is greater than 4 . For half blockage conditions, MIF is greater than 2, whereas for face B1, absolute MIF is greater than 7 with a negative sign, significance of which is that the nature of pressure is changed due to interference. MIF for face D3 is greater than 9 , which is maximum among all faces, and signifies that the effects of interference for full blockage conditions are maximum for face D3, which is a side front face toward the interfering building and falls in the wake zone of interfering buildings.

Interference effects for full blockage conditions are more severe for D3 among three critical faces. MIF for face D3 is greater than 13, which shows a large interference effect. Interference effect on this face is the most severe among all faces and all interference conditions, which can be explained by the fact that this face immerged in the wake region of interfering buildings corresponding to no blockage conditions and the velocity of flow increased after separating from the upwind interfering buildings due to which suction increases by a significant amount and results in a high value of the interference factor. According to Figure 17(b), the maximum value of RIF for surface average $C_{p, r m s}$ is 1.03 , which shows that the fluctuating component of pressure coefficient is not much affected due to the existence of an interfering building at three positions. Average of surface $C_{p, r m s}$ among all the surfaces is reduced due to the presence of the interfering building; however, peak values at the top level for some surfaces have increased, which may be due to vortex shedding for half blockage and no blockage conditions. From Figure 17(a), it is clear that interference effects are significant for three critical faces, namely A1, B1, and D3 for which IFs are very high; hence, the distribution of I.Fs herein only deals with the results for these three faces of the principal building. Figure 18 shows the contour of MIFs on these faces for three interference conditions, created due to different relative positions of the interfering building. In order to highlight the unfavorable positions of measuring points on the face, only those absolute $I . F s \geq 1$ are retained. For full blockage interference conditions, on face A1, I.Fs were distributed evenly on the surface from 0.51 to 2.31. Distribution on faces B1 and D3 is similar due to symmetry in position and wind flow around. Outer edges are significantly affected by interference, and from Figure 18(a), it is quite clear that the positions above the middle of the inner edge are favorable and regions of unfavorable locations concentrate on outer edges at $1 / 3$ height from the bottom. MIF for half blockage conditions on face A1 was distributed on bottom $2 / 3$ height with small variations, whereas variations at top $1 / 3$ height are significant and MIF varies from 1.67 to 4.27 . For face B1 and D3, distribution is similar; however, values slightly differ. MIF tends to increase near outer edges. The positions of favorable and unfavorable regions are similar as in the case of full blockage conditions. For no blockage interference conditions, the distribution of MIFs is quite different from previous conditions. A significantly large interference effect is noticed at face A1 and D3. MIF on face A1 is distributed evenly throughout the face and varies from 2.0 to 5.33 , whereas at face D3, MIF varies from 0.39 to 11.83 , and regions of unfavorable positions concentrate on the 


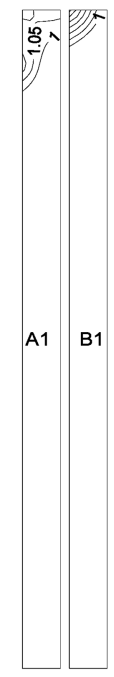

(a)

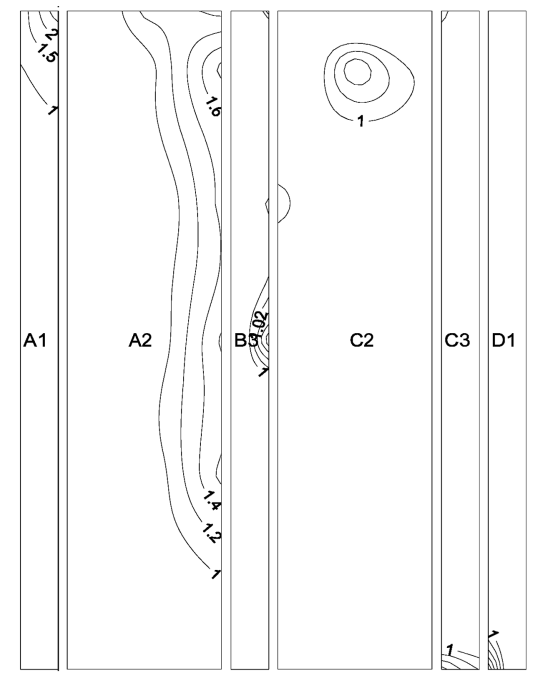

(b)

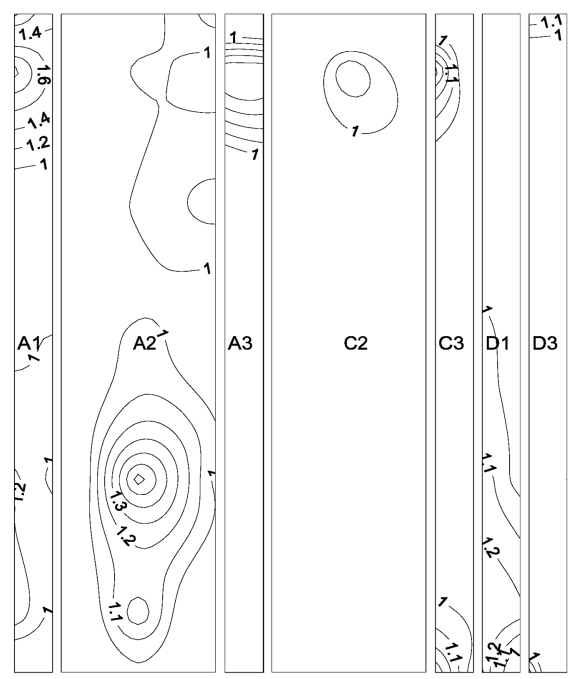

(c)

Figure 19. RMS Interference Factor (RIF) ( IF $\geq 1$ ) contour: (a) Full blockage, (b) half blockage, and (c) no blockage.

bottom half. Unfavorable measuring points at face B1 concentrate on the outer edge between a quarter and the half-height.

The distribution of RIFs is shown in Figure 19 for critical faces and unfavorable positions are highlighted by retaining $I F \geq 1$ only on the surfaces. From the figure, it is evident that for unfavorable full blockage regions concentrate on the corner part of the building surfaces. The maximum value is 1.13 . For half blockage distribution on the central surface, A2 is quite different from others because the boundary of the flow field at the back of interfering building lies at the center of this face. For no blockage interfering conditions, windward faces A1 and A2 and leeward face D1 are the most critical surfaces for which the larger area is covered by unfavorable positions.

\section{Conclusions}

Wind-induced proximity effects on $C_{p \text {,mean }}$ and $C_{p, r m s}$ between two identical plus-plan models were investigated in this study using detailed wind tunnel experiments. Three different interference conditions as full blockage, half blockage, and no blockage were considered, which were created by arranging two buildings in tandem and oblique configurations. The distribution of $C_{p \text {,mean }}$ on the surfaces of the principal building was presented as contour plots for isolated building and three interference conditions. Interference effects were presented by interference factors for $C_{p}$ at the face as Mean Interference Factor (MIF), and RMS Interference Factor (RIF) and contour of MIF and RIF were plotted for critical faces, where interference effects were significantly large. The following conclusion can be drawn from this study:
- Pressure distribution is symmetric for isolated building conditions and full blockage interference conditions, but does not remain symmetrical for half blockage and no blockage interference conditions;

- For isolated building conditions, side faces B2 and D2 have maximum pressure (suction) and the absolute value of average $C_{p \text {,mean }}$ at the face is 0.69 . The maximum face average value of $C_{p \text {,mean }}$ equal for full blockage condition is observed at the front face A2. For half blockage and no blockage, maximum values occur for the face B2 and A1, respectively;

- Interference effects are significant at faces on the windward side only at which interference factors are greater than unity. Interference factors at other faces are less than unity, demonstrating that pressure coefficients are reduced compared to isolated building conditions;

- The maximum MIF for full blockage conditions is greater than 4 and observed at side faces B2 and D2. For the half blockage condition, MIFs are significantly large at faces B1 and D3. Values are higher than 7 and 9 , respectively. However, for no blockage interference conditions, the largest value of MIF greater than 13 is observed at face D3, which is the largest among all interference conditions. RIF is more significant for no blockage conditions at face A1;

- Fluctuation in values of $C_{p \text {,mean at any level is }}$ large for measuring points on the windward side, immersed in the wake region of upwind interfering building;

- Interference effects for individual measuring points on the face are more critical for face A1, B1, and D3, at which MIFs are greater than 2. For face A1, MIF 
is distributed evenly, whereas face B1 and D3 regions of unfavorable locations concentrate on outer edges between $1 / 4$ and $1 / 2$ heights from the bottom except for no blockage conditions. Unfavorable regions corresponding to RIF have concentrated on corners parts of the building faces, except central windward face A2;

- The interference effect between closely spaced plusplan twin tall buildings still needs more in-depth study and investigations. The study of the effect of wind direction is also required in the future, which is not presented here because of the large content of the paper.

\section{Acknowledgments}

The authors gratefully acknowledge the Indian Institute of Technology, Roorkee (IITR), India, for providing the required infrastructure and resources to perform this research study.

\section{References}

1. Khanduri, A.C., Stathopoulos, T., and Bédard, C. "Wind-induced interference effects on buildings - a review of the state-of-the-art", Eng. Struct, 20, pp. 617-630 (1998).

2. Bhattacharyya, B. and Dalui S.K. "Experimental and numerical study of wind-pressure distribution on irregular-plan-shaped building", Journal of Structural Engineering, 146(7) p. 04020137 (2020).

3. Li, Yi, Li, Q.S., and Ju., K.L. "Experimental investigation of the wind pressure distribution and wind interference effects on a typical tall building", $A d$ vanced Materials Research, 639, pp. 444-451 Trans Tech Publications Ltd (2013).

4. Amin, J.A. and Ahuja, A.K. "Mean interference effects between two buildings: effects of close proximity", Struct. Design Tall Spec. Build., 20, pp. 832-852 (2011).

5. Amin, J.A. and Ahuja, A.K. "Wind-induced mean interference effects between two closed spaced buildings", KSCE Journal of Civil Engineering, 16, pp. 119-131 (2012).

6. Baily, P.A. and Kwok, K.C.S. "Interference excitation of twin tall buildings", J. Wind Eng. Ind. Aerodyne., 21, pp. 323-338 (1985).

7. Cho, K., Hong, S., and Hwang, K.S. "Effects of neighboring building on wind loads", In CTBUH 2004 Seoul Conference, pp. 516-523 (2004).

8. Khanduri, A.C., Stathopoulos, T., and Bédard, C. "Generalization of wind-induced interference effects for two buildings", Wind Struct., 3, pp. 255-266 (2000).

9. Kim, W., Tamura, Y., and Yoshida, A. "Interference effects on aerodynamic wind forces between two buildings", J. Wind Eng. Ind. Aerodyne., 147, pp. 186-201 (2015).
10. Mara, T.G., Terry, B.K., Ho, T.C.E., et al. "Aerodynamic and peak response interference factors for an upstream square building of identical height", J. Wind Eng. Ind. Aerodyne., 133, pp. 200-210 (2014).

11. Tse, K.T., Wang, D.Y., and Zhou, Y. "Wind pressure characteristics for a double tower high-rise structure in a group of buildings", Wind Struct., 5, pp. 491-515 (2013).

12. Wu, G., Du, X., and Wang, Y. "LES of flow around two staggered circular cylinders at a high subcritical Reynolds number of $1.4 \times 10^{5}$ ", J. Wind Eng. Ind. Aerodyne., 196, p. 104044 (2020).

13. Xie, Z.N. and Gu, M. "Mean interference effects among tall buildings", Eng. Struct., 26, pp. 1173-1183 (2004).

14. Xie, Z.N. and Gu, M. "A correlation-based analysis on wind-induced interference effects between two tall buildings", Wind Struct., 3, pp. 163-178 (2005).

15. Xie, Z.N. and Gu, M. "Simplified formulas for evaluation of wind-induced interference effects among three tall buildings", J. Wind Eng. Ind. Aerodyne., 95, pp. $31-52$ (2007).

16. Xing, Q. and Qian, J. "CFD analysis of wind interference effects of three high-rise buildings", Journal of Asian Architecture and Building Engineering, 17, pp. 487-494 (2018).

17. Yahyai, M., Kumar, K., Krishna, P., et al. "Aerodynamic interference in tall rectangular buildings", J. Wind Eng. Ind. Aerodyne., 41(1-3), pp. 859-866 (1992).

18. Zu, G.B. and Lam, K.M. "Across-wind excitation mechanism for interference of twin tall buildings in tandem arrangement", Wind Struct., 6, pp. 397-413 (2018a).

19. Kim, W., Tamura, Y., and Yoshida, A. "Simultaneous measurement of wind pressures and flow patterns for buildings with interference effect", Advances in Structural Engineering, 16(2), pp. 287-305 (2013).

20. Behera, S., Ghosh, D., Mittal, A.K., et al. "The effect of plan ratios on wind interference of two tall buildings", Struct. Design Tall Spec. Build., 29(1), p. e1680 (2020).

21. Dongmei, H., Xue, Z., Shiqing, H., et al. "Characteristics of the aerodynamic interference between two highrise buildings of different height and identical square cross-section", Wind Struct., 24, pp. 501-528 (2017).

22. Kim, B., Tse, K.T., and Tamura, Y. "POD analysis for aerodynamic characteristics of tall linked buildings", $J$. Wind Eng. Ind. Aerodyne., 181, pp. 126-140 (2018).

23. Kim, B. and Tse, K.T. "POD analysis of aerodynamic correlations and wind-induced responses of two tall linked buildings", Engineering Structures, 176, pp. 369-384 (2018).

24. Kim, B., Tse, K.T., Yoshida, A., et al. "Investigation of flow visualization around linked tall buildings with circular sections", Building and Environment, 153, pp. 60-76 (2019). 
25. Lam, K.M., Leung, M.Y.H., and Zhao, J.G. "Interference effects on wind loading of a row of closely spaced tall buildings", J. Wind Eng. Ind. Aerodyne., 96, pp. 562-583 (2008).

26. Yan, B. and Li, Q.S. "Wind tunnel study of interference effects between twin super-tall buildings with aerodynamic modifications", J. Wind Eng. Ind. Aerodyne., 156, pp. 129-145 (2016).

27. Yu, X.F., Xie, Z.N., Zhu, J.B., et al. "Interference effects on wind pressure distribution between two highrise buildings", J. Wind Eng. Ind. Aerodyne., 142, pp. 188-197 (2015).

28. Zhao, J.G. and Lam, K.M. "Interference effects in a group of tall buildings closely arranged in an L- or Tshaped pattern", Wind Struct., 11, pp. 1-18 (2008).

29. Zu, G.B. and Lam, K.M. "Shielding effects on a tall building from a row of and medium rise buildings", Wind Struct., 6, pp. 439-449 (2018b).

30. Hui, Y., Tamura, Y., and Yoshida, A. "Mutual interference effects between two high-rise building models with different shapes on local peak pressure coefficients", J. Wind Eng. Ind. Aerodyne., 104-106, pp. 98-108 (2012).

31. Hui, Y., Yoshida, A., and Tamura, Y. "Interference effects between two rectangular-section high-rise buildings on local peak pressure coefficients", Journal of Fluids and Structures, 37, pp. 120-133 (2013).

32. Kim, W., Tamura, Y., and Yoshida, A. "Interference effects on local peak pressures between two buildings", J. Wind Eng. Ind. Aerodyne., 99, pp. 584-600 (2011).

33. Macháček, M., Urushadze, S., Pospíšil, S., et al. "Aerodynamic interference of wind flow around three cylindrical bodies with surface roughness", In MATEC Web of Conferences, 313, p. 00051, EDP Sciences (2020).

34. Flaga, A., Kocoń, A., Kłaput, R., et al. "The environmental effects of aerodynamic interference between two closely positioned irregular high buildings", J. Wind Eng. Ind. Aerodyne., 180, pp. 276-287 (2018).

35. Kar, R. and Dalui, S.K. "Wind interference effect on an octagonal plan shaped tall building due to square plan shaped tall buildings", Int. J. Adv. Struct. Eng., 8, pp. 73-86 (2016).

36. Li, X. and Li, Q.S. "Wind-induced interference effects between twin tapered skyscrapers", Struct. Design Tall Spec. Build., 28(6), p. e1594 (2019).

37. Nagar, S.K., Raj, R., and Dev, N. "Experimental study of wind-induced pressures on tall buildings of different shapes", Wind and Structures, 31(5), pp. 431-443 (2020).

38. Zhang, L., Cheng, W., and Xie, Z. "Wind effect of a twin-tower super high-rise building with weak connection", Struct. Design Tall Spec. Build., 27(15), p. e1503 (2018).

39. Chen, J., Quan, Y., and Gu, M. "Aerodynamic interference effects of a proposed super high-rise building on the aerodynamic forces and responses of an existing building", J. Wind Eng. Ind. Aerodyne., 206, p. 104312 (2020).

40. Quan, Y., Chen, J., and Gu, M. "Aerodynamic interference effects of a proposed taller high-rise building on wind pressures on existing tall buildings", Struct. Design Tall Spec. Build., 29(4), p. e1703 (2020).

41. Farhadi, M. and Rahnama, M. "Large eddy simulation of separated flow over a wall-mounted cube", Scientia Iranica, 13(2), pp. 124-133 (2006).

42. Jing, W., Wang, J., and Cheng, X. "Dynamic responses of oil storage tank considering wind interference effect", Engineering Failure Analysis, 104, pp. 1053-1063 (2019).

43. Liang, Q.S., Fu, J.Y., Li, Z., et al. "Bimodal distribution of wind pressure on windward facades of highrise buildings induced by interference effects", J. Wind Eng. Ind. Aerodyne., 200, p. 104156 (2020).

44. Sun, Y., Li, Z., Sun, X., et al. "Interference effects between two tall chimneys on wind loads and dynamic responses", J. Wind Eng. Ind. Aerodyne., 206, p. 104227 (2020).

45. Tavakol, M.M. and Yaghoubi, M. "Experimental and numerical analysis of turbulent air flow around a surface mounted hemisphere", Scientia Iranica, 17(6), pp. 480-491 (2010).

46. Gu, M. and Xie, Z.N. "Interference effects of two and three super-tall buildings under wind action", Acta Mech Sin, 27, pp. 687-696 (2011).

47. Lim, J. and Bienkiewicz, B. "Wind tunnel investigation of correlation and coherence of wind loading on generic tall twin buildings in close proximity", Wind Struct., 4, pp. 443-456 (2014).

48. Sy, L.D., Yamada, H., and Katsuchi, H. "Interference effects of wind-over-top flow on high-rise buildings", $J$. Wind Eng. Ind. Aerodyne., 187, pp. 85-96 (2019).

49. Taniike, Y. "Interference mechanism for enhanced wind forces on neighboring tall buildings", J. Wind Eng. Ind. Aerodyne, 42, pp. 1073-1083 (1992).

50. Yu, X.F., Xie, Z.N., Wang, X., et al. "Interference effects between two high-rise buildings on wind-induced torsion", J. Wind Eng. Ind. Aerodyne., 159, pp. 123133 (2016).

51. Yu, X., Xie, Z., and Gu, M. "Interference effects between two tall buildings with different section sizes on wind-induced acceleration", J. Wind Eng. Ind. Aerodyne., 182, pp. 16-26 (2018).

52. Zu, G.B. and Lam, K.M. "Across-wind excitation mechanism for interference of twin tall buildings in staggered arrangement", J. Wind Eng. Ind. Aerodyne., 177, pp. 167-185 (2018).

53. Germi, M.S. and Kalehsar, H.E. "Numerical investigation of interference effects on the critical wind velocity of tall buildings", Structures, 30, pp. 239-252, Elsevier (2021). 
54. Blessmann, J. "Neighbouring wind effects on two tall buildings", J. Wind Eng. Ind. Aerodyne., 41-44, pp. 1041-1052 (1992).

55. Wong, S.Y. and Lam, K.M. "Effect of recessed cavities on wind-induced loading and dynamic responses of a tall building", J. Wind Eng. Ind. Aerodyne., 114, pp. 72-82 (2013).

56. Meng, F.Q., He, B.J., Zhu, J., et al. "Sensitivity analysis of wind pressure coefficients on CAARC standard tall buildings in CFD simulations", Journal of Building Engineering, 16, pp. 146-158 (2018).

57. Zhao, D.X. and He, B.J. "Effects of architectural shapes on surface wind pressure distribution: case studies of oval-shaped tall buildings", Journal of Building Engineering, 12, pp. 219-228 (2017).

58. Li, S.L., Liu, L.L., Wu, H., et al. "New test method of wind pressure coefficient based on CAARC standard model determined using vehicle driving wind", Experimental Techniques, 43(6), pp. 707-717 (2019). https://doi.org/10.1007/s40799-019-00330-2

\section{Biographies}

Suresh Kumar Nagar is currently a PhD student at the Department of Civil Engineering, Delhi Technological University, Delhi, India and Assistant Professor at Department of Civil Engineering, Rajasthan Technical University, Kota, Rajasthan, India. He received his BE from the M.B.M Engineering College, Jai Narain Vyas University, Jodhpur, India in the field of Civil
Engineering in 2009 and his ME in the field of Structural Engineering from Delhi University in 2011. His research interests include structural analysis, Wind effects on tall buildings, CFD. He has published 20 research paper in journals and conferences.

Ritu Raj is an Assistant Professor at the Civil Engineering Department, DTU. He has published more than 50 technical papers in reputable journals and international conferences. He has supervised many students at the level of graduates, postgraduates, and doctorates. His research interests include behavior of wind load on the response of tall building, aerodynamics study, aero-elastic model study inside BLWT, behavior of high strength concrete with and without fiber, and earthquake engineering. He has more than 7.5 years of graduate and post-graduate teaching experience. His teaching areas include: structure engineering, strength of materials, steel structures, and design of tall buildings.

Nirendra Dev is a Professor at Civil Engineering Department, DTU. He has more than 35 years of academic and educational administration experience. He has published numerous research paper in reputable journals and international conferences. His research interest includes behavior of high strength concrete with and without fiber, earthquake engineering, and concrete technology. He has supervised more than 45 students in gradates, post-graduates, and doctorates levels. 